\title{
PRODUÇÃO DE SEMENTES DE CEVADILHA-VACARIANA (Bromus auletius Trinius) EM FUNÇÃO DA CRONOLOGIA DE DESENVOLVIMENTO DOS PERFILHOS REPRODUTIVOS ${ }^{1}$
}

\author{
MANOELDE SOUZAMAIA², GUSTAVO MARTINS DASILVA ${ }^{3}$, SILMAR TEICHERT PESKE ${ }^{4}$, \\ CARLOS OTÁVIO COSTAMORAES ${ }^{5}$, RENATOBORGESDE MEDEIROS ${ }^{6}$
}

\begin{abstract}
RESUMO - As pastagens naturais são um importante recurso utilizado para sustentar a produção pecuária da região sul do Brasil. Contudo, por serem constituídas em sua maior parte de espécies estivais, paralisam seu crescimento e perdem a qualidade no período de outono-inverno, causando elevados prejuízos econômicos. Bromus auleticus é uma gramínea perene de clima temperado, cuja contribuição forrageira ocorre no período de maior carência alimentar do rebanho sul-brasileiro. $\mathrm{O}$ objetivo do trabalho foi avaliar os componentes da quantidade e a qualidade de sementes de $B$. auleticus, em função da ordem cronológica de desenvolvimento dos perfilhos. Foram selecionadas 30 plantas representativas, as quais tiveram seus perfilhos marcados em função da ordem cronológica de diferenciação e alongamento dos entre-nós. A colheita de sementes aconteceu de acordo com a maturação de cada perfilho, em geral 30 dias após a antese máxima. A ordem cronológica de desenvolvimento dos perfilhos determina a produção de sementes de B. auleticus. A produção de sementes de $B$. auleticus é similar nos três primeiros perfilhos que se desenvolvem em uma planta, sendo responsáveis por aproximadamente $75 \%$ do rendimento final. Esses perfilhos reprodutivos são mais altos, apresentam maior número de sementes por panícula, maior peso e germinação de sementes e menor dormência em relação aos demais perfilhos da mesma planta.
\end{abstract}

Termos para indexação: pastagem hibernal, nativa, dormência.

\section{SEED PRODUCTION OF Bromus auletius Trinius ACCORDINGTOTHECHRONOLOGY OFTILLER DEVELOPMENT}

\begin{abstract}
Native pastures constitute the feed basis for livestock in Southern Brazil. These natural grazing fields are constituted mainly by summer species, paralyzing their growth and loosing quality in the autumn-winter period. This factor causes high economic losses to the livestock producers. Bromus auleticus is a temperate climate perennial grass, whose contribution to forage occurs at a time of crucial feeding needs of the herds. The objective of the present study was to evaluate the yield components and the quality of $B$. auleticus seeds according to the chronological order of reproductive tiller development. Thirty representative plants were selected and their tillers were labeled according to the chronological order of differentiation and elongation. Harvesting was done at the time of full maturation of each tiller, generally 30 days after maximum anthesis. The chronological order of tiller development determined the yield of Bromus auleticus seeds. Seed yield of $B$. auleticus was similar in the first, second and third tillers which developed in a plant, being responsible for about $75 \%$ of the yield. These reproductive tillers were taller and had more seeds per panicle, heavier and higher germinating seeds, and had less seed dormancy than the other tillers on the same plant.
\end{abstract}

Index terms: winter pasture, native, dormancy.

\footnotetext{
${ }^{1}$ Submetido em 10/10/2005. Aceito para publicação em 01/08/2006. Parte da Tese de Doutorado do segundo autor apresentada à Universidade Federal de Pelotas - UFPel;

${ }^{2}$ Eng. Agrônomo, Dr., Professor Adjunto, Departamento de Fitotecnia, Faculdade de Agronomia Eliseu Maciel, UFPel, Caixa Postal 354, CEP: 96010-900, Pelotas - RS, maiams@ufpel.tche.br;

${ }^{3}$ Eng. Agrônomo, Dr. em Ciência e Tecnologia de Sementes pela UFPel, elguapo@ufpel.tche.br;
}

${ }^{4}$ Eng. Agrônomo, Ph.D., Professor Titular, Departamento de Fitotecnia, Faculdade de Agronomia Eliseu Maciel, UFPel, Pelotas - RS, peske@ufpel.tche.br;

${ }^{5}$ Eng. Agrônomo, M.Sc., Pesquisador da Embrapa Pecuária Sul, BR 153 km 595, Caixa Postal 242, Bagé - RS, comoraes@cppsul.embrapa.br;

${ }^{6}$ Eng. Agrônomo, Dr., Professor Adjunto, Departamento de Meteorologia e Plantas Forrageiras, Faculdade de Agronomia, Universidade Federal do Rio Grande do Sul, Porto Alegre - RS, medeiror@orion.ufrgs.br. 


\section{INTRODUÇÃO}

As pastagens naturais são importantes recursos utilizados para sustentar a produção pecuária da região sul do Brasil, já que aproximadamente $77 \%$ dos animais são alimentados exclusivamente com a forragem produzida nessas formações vegetais (Barcellos et al., 2002; Maia et al., 2003). Por serem constituídas em sua maior parte de espécies estivais, paralisam seu crescimento e perdem a qualidade no período de outonoinverno, causando elevados prejuízos econômicos com a diminuição dos índices de produtividade animal (Brasil, 2000).

Bromus auleticus Trinius, também chamada cevadilhavacariana, é uma gramínea perene de clima temperado, cuja contribuição forrageira ocorre no período de maior carência alimentar do rebanho sul-brasileiro. Essa espécie está presente de forma natural, amplamente dispersa no Estado do Rio Grande do Sul, Uruguai e Argentina (Garcia, 1988).

Os aspectos reprodutivos de uma espécie de interesse agronômico são de grande importância, mesmo tratando-se de uma com potencial forrageiro. Bromus auleticus apresenta, em geral, produção de sementes abundante a partir do segundo ano, sendo $395 \mathrm{~kg} \cdot \mathrm{ha}^{-1}$ a média de 14 diferentes genótipos, em diferentes locais e anos de colheita (Boggiano e Zanoniani, 2001). Ao avaliarem uma coleção de 54 acessos de $B$. auleticus, Moraes e Oliveira (1990) constataram que todos os genótipos apresentaram potencial para produzir sementes viáveis.

Contudo, algumas características específicas identificadas nessa espécie merecem elucidação, como a grande quantidade de espiguetas vazias e as deformadas que ficam hipertrofiadas, não desempenhando função reprodutiva (Olmos, 1993; Silva, 2001).

Sabe-se que um dos principais componentes da produção de sementes é o número de inflorescências por área (Carámbula, 1981; Silva, 2001). Lambert e Jewiss (1970) consideraram que, de forma geral, a produção de sementes de gramíneas forrageiras perenes de clima temperado depende basicamente do número de perfilhos formados, do tempo em que esses perfilhos se desenvolvem, da proporção dos mesmos onde houve diferenciação de flor e do tamanho final das inflorescências. B. auleticus apresenta alto potencial de perfilhamento, podendo desenvolver até 59 perfilhos por planta (Davies, 1990).

Diversos fatores podem interferir no processo de perfilhamento, tais como, genótipo, temperatura, fotoperiodismo, nutrição mineral, suprimento de água, fitormônios e práticas culturais de manejo. Em gramíneas, a época de formação de um perfilho está altamente relacionada a sua posição na planta-mãe e quanto mais tardio é o desenvolvimento, mais o perfilho sofre com a competição por luz e outros recursos necessários ao seu desempenho produtivo. Assim, vários pesquisadores verificaram que os primeiros perfilhos a se desenvolver têm maior capacidade de gerar inflorescências, com maior produção de sementes (Carámbula, 1981).

O objetivo do presente trabalho foi avaliar os componentes da quantidade e a qualidade de sementes de Bromus auleticus, em função da ordem cronológica de desenvolvimento dos perfilhos reprodutivos.

\section{MATERIAL E MÉTODOS}

Os trabalhos de campo foram conduzidos na Embrapa Pecuária Sul, em Bagé-RS, em área semeada com Bromus auleticus no ano de 1995 que se manteve, desde então, como espécie dominante. Segundo o Banco Ativo de Germoplasma - BAG, esse material constitui o acesso Limoeiro, proveniente da região de Bagé-RS, que tem sido identificado como um dos mais produtivos (Silveira et al., 2002). Para efeito do presente trabalho, a área foi dividida em três níveis, em função da declividade do terreno.

A amostragem realizada foi estratificada preferencial (Kenkel et al., 1989). Desta forma, foram selecionadas 10 plantas em cada um dos três níveis do terreno; as plantas que constituíram a amostra eram representativas da população, porém apresentavam pelo menos cinco perfilhos reprodutivos no momento da seleção. Cada amostra ficou constituída dos perfilhos de mesma ordem, colhidos no mesmo nível do terreno.

Os perfilhos de cada planta foram marcados em função da ordem cronológica de diferenciação - do estádio vegetativo para o reprodutivo - e alongamento dos entrenós. O primeiro perfilho da planta a desenvolver estes eventos foi considerado de primeira ordem e assim sucessivamente. A antese máxima ocorreu cerca de 20 dias após o início da marcação de plantas e perfilhos. A colheita de sementes aconteceu de acordo com a maturação de cada perfilho, em geral 30 dias após a antese, quando a umidade das sementes era aproximadamente 35\% (Silva, 2001; Tamanini, 2002). As médias mensais de precipitação pluvial e temperatura no ano de 2002 encontramse na Tabela 1.

As panículas foram colhidas manualmente e em separado, de acordo com a ordem dos perfilhos. Foram registrados o número e a altura dos perfilhos reprodutivos por planta. $\mathrm{O}$ 
TABELA 1. Precipitações pluviais e temperaturas médias mensais, registradas na região de Bagé-RS, no ano de 2002.

\begin{tabular}{lcc}
\hline & Precipitação $(\mathrm{mm})$ & Temperatura $\left({ }^{\circ} \mathrm{c}\right)$ \\
\hline Janeiro & 214,6 & 21,81 \\
Fevereiro & 106,0 & 20,70 \\
Março & 187,4 & 22,27 \\
Abril & 277,5 & 16,98 \\
Maio & 73,2 & 15,90 \\
Junho & 148,5 & 11,05 \\
Julho & 126,4 & 11,18 \\
Agosto & 227,0 & 13,77 \\
Setembro & 224,0 & 13,09 \\
Outubro & 284,0 & 18,28 \\
Novembro & 120,9 & 19,39 \\
Dezembro & 398,8 & 20,58 \\
\hline
\end{tabular}

material colhido foi secado naturalmente à sombra, em local arejado e depois levado ao Laboratório Didático de Análise de Sementes "Prof. Flávio Farias Rocha", Departamento de Fitotecnia da Faculdade de Agronomia Eliseu Maciel, Universidade Federal de Pelotas. Em cada amostra, foram realizadas as seguintes avaliações:

Número de espiguetas hipertrofiadas por panícula foram contadas as espiguetas que se apresentavam deformadas e o número verificado foi considerado em relação ao número de panículas da amostra; Pureza física de sementes separação das sementes cheias, constituindo a porção "semente pura", vazias e material inerte, com pesagem de cada fração. A razão entre o peso da porção "semente pura" e o peso total foi transformada em porcentual de pureza; Número de sementes por panícula - contagem das sementes da porção "semente pura" e o resultado foi considerado em relação ao número de panículas da amostra; Massa de 1000 sementes - considerando-se a massa e o número de sementes da porção "semente pura" da amostra, obteve-se a massa de 1000 sementes através de cálculo matemático; Rendimento - multiplicação do número de perfilhos reprodutivos encontrados pelo número médio de sementes por panícula para obtenção do número total de sementes da amostra. O resultado foi relacionado com a massa média de 1000 sementes para obtenção do rendimento da amostra; Teste de germinação - realizado sobre-papel previamente umedecido com água, em temperatura constante de $18^{\circ} \mathrm{C}$ e 8 horas de luz por dia (Silva, 2001). As contagens foram realizadas aos 10 e 21 dias após a semeadura. Nas amostras em que havia número de sementes suficiente, foram utilizadas duas subamostras de 50 sementes; nas demais amostras utilizaram-se todas as sementes disponíveis.
Considerou-se como resultado o porcentual de plântulas normais, verificado no final do teste; Dormência de sementes - no final do teste de germinação, as sementes não germinadas que se apresentavam intactas e sem sinais de deterioração foram consideradas sementes dormentes. O resultado da contagem dessas sementes foi transformado para valor porcentual;

$\mathrm{Na}$ análise estatística dos dados foi utilizado o programa MULTIV versão 2.1.1 (Pillar, 2001). Para esse procedimento, todos os perfilhos de mesma ordem constituíram uma unidade amostral e as variáveis caracterizaram essas unidades. Os dados foram submetidos à transformação vetorial "normalização", dentro de variáveis. Utilizou-se a distância euclidiana como medida de semelhança entre as unidades amostrais. A análise de agrupamentos foi realizada pelo método de "ligação simples" e para observar a existência de um padrão de distribuição das unidades amostrais, foi utilizada a ordenação multidimensional através do método de "coordenadas principais". Com o objetivo de verificar a veracidade da hipótese nula (Ho), de que não há diferença na produção de sementes em função dos fatores observados "nível do terreno" e "ordem dos perfilhos", efetuou-se a análise de variância e o teste de aleatorização. Todos os perfilhos de mesma ordem, em cada nível do terreno, constituíram uma unidade amostral. Utilizaram-se 1000 interações e nível de significância $\mathrm{a}=0,05$.

\section{RESULTADOS E DISCUSSÃO}

$\mathrm{Na}$ análise de agrupamentos e ordenação multidimensional foram utilizadas as médias de todos os perfilhos avaliados de cada ordem, conforme Tabela 2. Assim, foram consideradas oito unidades amostrais, representando os perfilhos até a oitava ordem. Verificaram-se somente dois perfilhos reprodutivos de nona ordem e um de décima ordem; uma análise estatística preliminar mostrou que podiam ser desconsiderados em função da insuficiência amostral.

Constatou-se que as partições em dois, três e quatro grupos foram significativas, conforme Figura 1. A formação de quatro grupos foi escolhida, pois se apresentou mais nítida no gráfico de distribuição de pontos (Figura 2). Desta forma, a produção de sementes de Bromus auleticus foi relativamente similar nos perfilhos de primeira, segunda e terceira ordens, variando a partir da quarta ordem. A Tabela 2 mostra que os perfilhos desse grupo $\left(1^{\mathrm{a}}, 2^{\mathrm{a}}\right.$ e $3^{\mathrm{a}}$ ordens $)$ foram mais altos, produziram maior número de sementes por panícula, maior peso de sementes, maior germinação e menor dormência.

Considerando-se o número de perfilhos reprodutivos encontrados nas 30 plantas, o número de sementes por 
TABELA2. Número de perfilhos reprodutivos (NPR), altura dos perfilhos reprodutivos (APR), número de espiguetas hipertrofiadas por panícula (NEH), pureza de sementes (PS), número de sementes por panícula (NS), peso de 1000 sementes (P1000), rendimento (R), germinação (G) e dormência (D) de sementes de Bromus auleticus, em função da ordem cronológica dos perfilhos reprodutivos (OCPR).

\begin{tabular}{cccccccccc}
\hline OCPR & NPR & $\begin{array}{c}\text { APR } \\
(\mathrm{cm})\end{array}$ & NEH & $\begin{array}{c}\text { PS } \\
(\%)\end{array}$ & NS & $\begin{array}{r}\text { P1000 } \\
(\mathrm{g})\end{array}$ & $\begin{array}{r}\mathrm{R} \\
(\mathrm{g})\end{array}$ & $\begin{array}{r}\mathrm{G} \\
(\%)\end{array}$ & $\begin{array}{c}\mathrm{D} \\
(\%)\end{array}$ \\
\hline $1^{\mathrm{a}}$ & 28 & 114 & 0,4 & 63,6 & 85 & 6,06 & 14,42 & 18 & 71 \\
$2^{\mathrm{a}}$ & 28 & 109 & 0,7 & 66,2 & 81 & 6,08 & 13,79 & 16 & 73 \\
$3^{\mathrm{a}}$ & 25 & 103 & 0,6 & 59,6 & 55 & 5,82 & 8,00 & 13 & 77 \\
$4^{\mathrm{a}}$ & 23 & 94 & 0,2 & 63,9 & 40 & 5,81 & 5,35 & 10 & 79 \\
$5^{\mathrm{a}}$ & 14 & 91 & 1,1 & 57,4 & 31 & 5,13 & 2,23 & 3 & 87 \\
$6^{\mathrm{a}}$ & 9 & 95 & 1,9 & 61,8 & 43 & 5,17 & 2,00 & 8 & 82 \\
$7^{\mathrm{a}}$ & 7 & 91 & 1,0 & 65,4 & 37 & 4,49 & 1,16 & 6 & 91 \\
$8^{\mathrm{a}}$ & 5 & 88 & 0,2 & 73,3 & 44 & 4,91 & 1,08 & 6 & 87 \\
\hline Média & & 98 & 0,8 & 63,9 & 52 & 5,43 & 6,00 & 10 & 81 \\
\hline
\end{tabular}

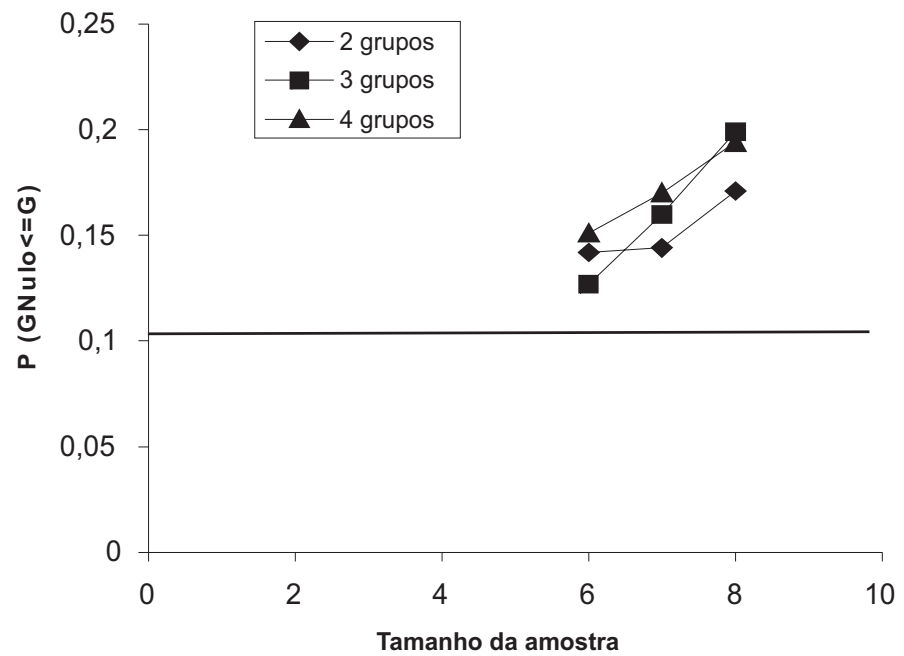

FIGURA1. Avaliação da suficiência amostral e probabilidade de partição em 2, 3 ou 4 grupos, obtidos pela reamostragem.

panícula e o peso de 1000 sementes (Tabela 2), constatou-se que os três primeiros perfilhos de cada planta foram responsáveis por $75 \%$ do rendimento de sementes. Além disso, considerando que também foram registrados muitos perfilhos de quarta ordem, pode-se acrescentá-los aos cálculos, obtendo-se aumento no rendimento para $86 \%$.

De maneira similar, Hill e Watkin (1975), trabalhando com Bromus unioloides, Lolium perenne e Phleum sp., verificaram que a época de emissão da inflorescência influenciou os componentes da produção de sementes, sendo que os primeiros perfilhos reprodutivos formados proporcionaram maior rendimento. Portanto, o manejo para a colheita de sementes ou ressemeadura natural deve privilegiar

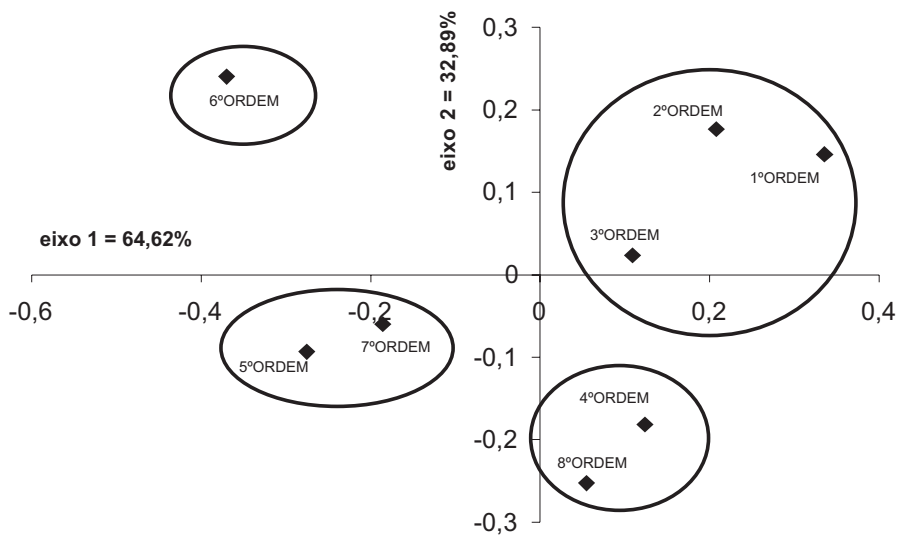

FIGURA 2. Diagrama de dispersão das unidades amostrais, que representam os perfilhos reprodutivos de Bromus auleticus de diferentes ordens cronológicas, definido por duas dimensões.

as sementes produzidas por esse grupo de perfilhos.

Na análise de variância acoplada ao teste de aleatorização, utilizaram-se as médias somente dos perfilhos até a quinta ordem, pois em um dos níveis do terreno as plantas marcadas não apresentaram mais do que 5 perfilhos reprodutivos. Assim, consideraram-se 15 unidades amostrais, representando os 3 níveis do terreno e as 5 ordens cronológicas dos perfilhos. Os resultados mostraram que o fator observado "nível do terreno" não foi significativo; entretanto, o fator observado "ordem dos perfilhos" influiu na produção de sementes de Bromus auleticus, caracterizada por todas as variáveis avaliadas.

Com o objetivo de analisar quais variáveis foram mais 
importantes, como causa da variação observada em função da ordem dos perfilhos, foram construídos gráficos independentes para cada componente da produção de sementes.

A Figura 3 mostra tendência de diminuição da altura dos perfilhos reprodutivos com o aumento da ordem cronológica de desenvolvimento. Em média, a redução foi de aproximadamente $5 \%$ a cada ordem. Esse resultado podia ser observado no campo, onde visualmente os primeiros perfilhos eram maiores do que os demais, em uma mesma planta.

A variável "número de espiguetas hipertrofiadas por panícula" não mostrou relação com a ordem dos perfilhos, já que não apresentou resposta que permitisse algum entendimento (Tabela 2). Também, observou-se no campo que panículas em distintos estágios de maturação apresentavam essa deformação. A "pureza de sementes" foi outra variável que não mostrou relação com o fator observado. Na Tabela 2, observa-se que os valores foram muito próximos e não permitiram identificar alguma relação que possa existir. Assim, esses dois aspectos identificados por alguns pesquisadores como problemáticos na produção de sementes de Bromus auleticus (Riveiro e Petit, 1982; Olmos, 1993), provavelmente não são afetados pela ordem cronológica dos perfilhos.

O número de sementes por panícula foi influenciado pela ordem dos perfilhos, com redução média de aproximadamente $15 \%$ a cada ordem, conforme Figura 4 . Com relação à variável "massa de 1000 sementes", também ocorreu diminuição de aproximadamente $15 \%$ a cada ordem dos perfilhos (Figura 5). Weiner (1988) considerou que o número de sementes cheias é uma variável mais "sensível" do que a massa de sementes; desta forma, a tendência seria priorizar a manutenção de um peso mínimo, em detrimento da quantidade

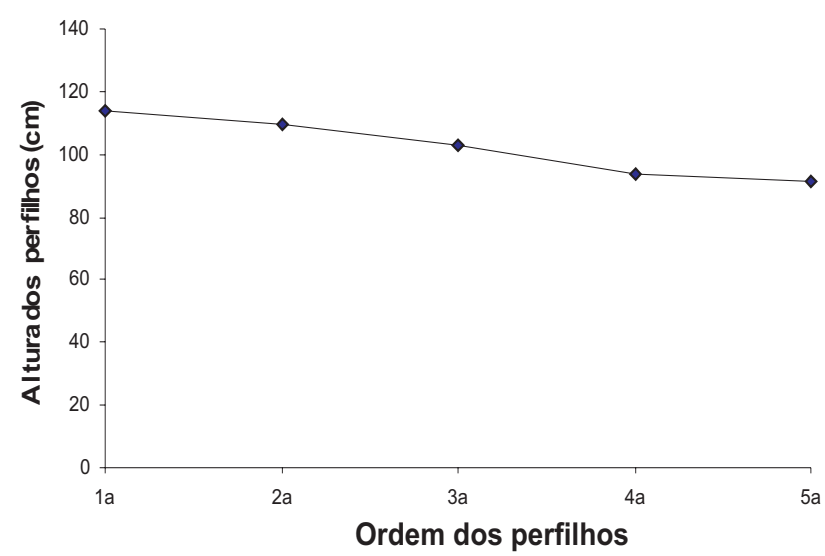

FIGURA 3. Altura dos perfilhos reprodutivos de Bromus auleticus, em função da ordem cronológica de desenvolvimento. de sementes. Entretanto, na Tabela 2, observa-se que houve certa estabilidade no número de sementes por panícula, a partir da quarta ordem.

As respostas das variáveis "germinação" e "dormência de sementes" foram antagônicas (Figura 6), com coeficiente de correlação negativo alto $(-0,94)$. Observa-se que a germinação das sementes recém colhidas dos perfilhos de menor ordem tende a ser maior em relação aos perfilhos de maior ordem; inversamente à dormência, já que sementes colhidas dos primeiros perfilhos apresentaram menor dormencia. Esse resultado parece indicar uma forma de sobrevivência da espécie, em caso de condições totalmente adversas ao estabelecimento das plantas no período que seria o mais favorável. Assim, com sementes mais dormentes, a espécie garantiria a germinação de pelo menos algumas

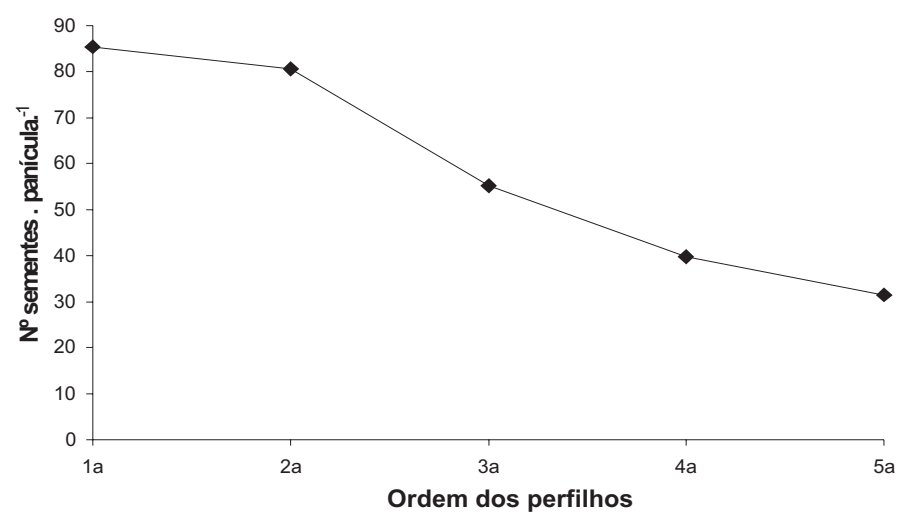

FIGURA 4. Número de sementes de Bromus auleticus por panícula, em função da ordem cronológica dos perfilhos reprodutivos.

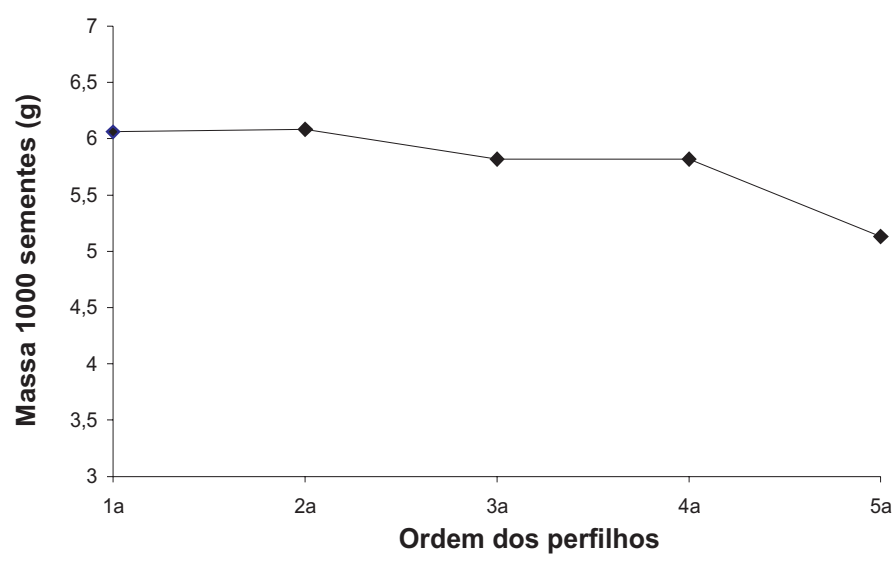

FIGURA 5. Massa de 1000 sementes de Bromus auleticus, em função da ordem cronológica dos perfilhos reprodutivos. 


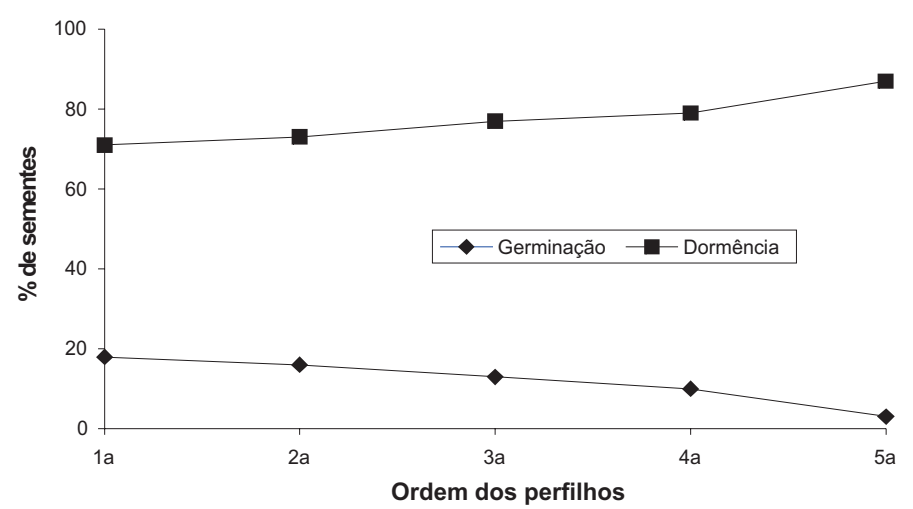

FIGURA 6. Germinação e dormência de sementes de Bromus auleticus, em função da ordem cronológica dos perfilhos reprodutivos.

sementes em um momento posterior, possivelmente mais adequado (Murdoch e Ellis, 2000).

A germinação seqüencial de sementes pode significar um mecanismo de dispersão temporal que reduz a competição intraprogênie (Ellner e Shmida, 1981). Essa seria outra hipótese para justificar o resultado verificado no presente trabalho, permitindo inferir que Bromus auleticus apresenta estratégia regenerativa de evitar a competição entre indivíduos descendentes de uma mesma planta.

Plântulas que emergem sob uma camada espessa de palha gastam grande parte de sua energia para atingir a luz e, se forem oriundas de sementes pequenas, podem não sobreviver devido à baixa quantidade de reservas (Theisen, 1998). Diversos trabalhos têm associado o vigor de sementes ao seu peso (Hampton, 1986; Silva et al., 2003). Essas considerações podem explicar a relação inversa verificada entre as variáveis "peso" e "dormência de sementes", representada pelo alto coeficiente de correlação negativo de $-0,96$. Ou seja, em função de menor chance de sobrevivência sob condições adversas, as sementes menos pesadas podem requerer condições mais específicas para a superação da dormência, permitindo a germinação somente em uma situação mais favorável.

Além disso, é importante ressaltar que o grau de dormência pode também ser modificado por fatores ambientais durante o desenvolvimento da planta-mãe. Burghardt e Froud-Williams (1996) verificaram aumento na dormência de sementes de Bromus diandrus em situação de falta de água durante a maturação. Em trigo, temperaturas acima de $25^{\circ} \mathrm{C}$ durante o estágio de massa mole da semente, reduzem sensivelmente o nível de dormência (Nedel, 2003). No ano de realização do presente trabalho, infere-se que fatores ambientais como temperatura e umidade não foram determinantes de grau de dormência diferente do normal para a espécie (Tabela 1), já que as médias anuais históricas na região são de $1300 \mathrm{~mm}$ de precipitação e $17,6^{\circ} \mathrm{C}$ de temperatura (Oliveira e Moraes, 1993).

Na Figura 7 pode ser observada a área experimental no dia 31 de outubro de 2002, quando as sementes estavam em processo de maturação. As fases de desenvolvimento dos perfilhos reprodutivos podem ser visualizadas na Figura 8.

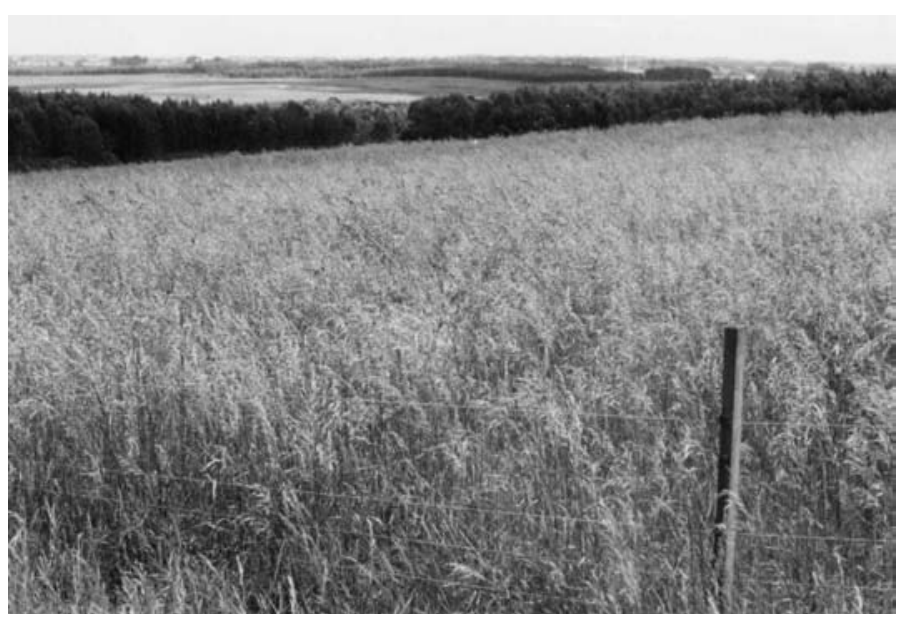

FIGURA 7. Área experimental com Bromus auleticus, quando as sementes estavam em processo de maturação. Embrapa Pecuária Sul, Bagé-RS.

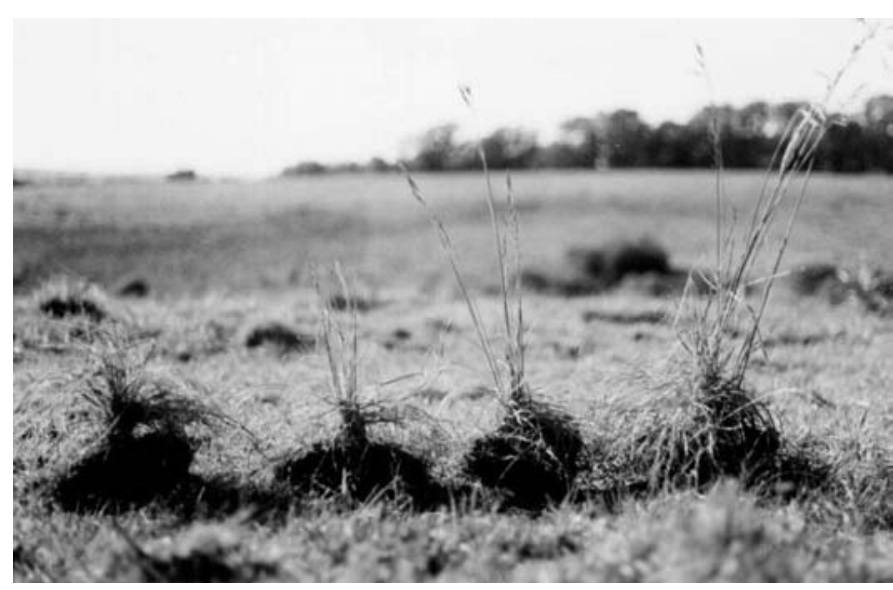

FIGURA 8. Fases de desenvolvimento de perfilhos reprodutivos em Bromus auleticus. 


\section{CONCLUSÕES}

A ordem cronológica de desenvolvimento dos perfilhos reprodutivos determina a produção de sementes de Bromus auleticus.

A produção de sementes de Bromus auleticus é similar nos três primeiros perfilhos reprodutivos que se desenvolvem em uma planta, os quais são responsáveis por aproximadamente $75 \%$ do rendimento final.

Os três primeiros perfilhos reprodutivos, que se desenvolvem em uma planta de Bromus auleticus, apresentam maior altura, maior número de sementes por panícula, maior peso e germinação de sementes e menor dormência de sementes em relação aos demais perfilhos reprodutivos da mesma planta.

\section{REFERÊNCIAS}

BARCELLOS, J.O.J.; PRATES, E.R.; SILVA, M.D.; MONTANHOLI, Y.R.; WUNSCH, C. Sistemas pecuários no sul do Brasil - "zona campos": tecnologias e perspectivas. In: Reunión de Grupo Técnico en Forrajeras del Cono Sur - Zona Campos. Sistemas de producción: caminos para una integración sustentable, 19., 2002, mercedes, Argentina. Memorias... Mercedes: FAO, 2002. p.10-15.

BOGGIANO, P.; ZANONIANI, R.A. Producción de semilla de Bromus auleticus Trinius. Consideraciones generales. In: DIALOGO - Los Recursos Fitogeneticos del Genero Bromus en el Cono Sur, 56., 2001, Montevideo. Anais... Montevideo: PROCISUR, 2001. p.29-34.

BRASIL. Ministério da Agricultura. Melhoria da oferta forrageira para a Região Sul - Novas tecnologias. Bagé: EMBRAPA/CNPO, 2000. 62p. (Documentos, 19).

BURGHARDT, F.; FROUD WILLIAMS, R.J. Effect of water stress and temperature on growth, transpiration and stomatal frequency in Bromus sterilis and B. diandrus. Implications of "Global environmental change" for crops in Europe. Cambridge: Churchill College, 1996. p.219-226.

CARÁMBULA, M. Producción de semillas de plantas forrajeras. Montevideo: Hemisferio Sur, 1981. 516p.

DAVIES, P. Efecto del nivel de nitrogenio y densidad de siembra en Bromus auleticus. In: SEMINARIO NACIONAL DE CAMPO NATURAL, 2., 1990, Tacuarembo. Anais... Tacuarembo: INIA/ Sociedad Uruguaya de Pasturas Naturales, 1990. p.105-114.

ELLNER, S.; SHMIDA, A. Why are adaptations for long-range seed dispersal rare in desert plants? Ecologia, New York, v.51, p.133-144, 1981.

GARCIA, J. Variedades forrajeras. In: Jornada de Forrajeras, 1988, Colonia del Sacramiento. Anais... Colonia del Sacramiento: Centro de Investigaciones Agricolas “Alberto Boerger"/Estación Experimental La Estanzuela, 1988. p.1-3.

HAMPTON, J.G. Effect of seed lot 1000-seed weight on vegetative and reprodutive yields of "Grassland Moata" tetraploid italian ryegrass (Lolium multiflorum). New Zealand Journal of Experimental Agriculture, Wellington, v.14, n.1, p.13-8, 1986.

HILL, M.J.; WATKIN, B.R. Seed production studies on perennial ryegrass, timothy and prairie grass. Effect of tillers age on tiller survival, ear emergence and seedhead components. Journal of British Grassland Society, Bershire, v.30, p.63-71, 1975.

KENKEL, N.C.; JUHÁSZ-NAGY, P.; PODANI, J. On sampling procedures in population and community ecology. Vegetatio, Neuchâtel, v.83, p.195-207, 1989.

LAMBERT, D.A.; JEWISS, O.R. The position in the plant and the date of origin of tillers which produce inflorescence. Journal of British Grassland Society, Bershire, v.25, n.2, p.107-12, 1970.

MAIA, F.C.; MEDEIROS, R.B.; PILLAR, V.P.; FOCHT, T.; CHOLLET, D.M.S.; OLMEDO, M.O.M. Composição, riqueza e padrão de variação do banco de sementes do solo em função da vegetação de um ecossistema de pastagem natural. Iheringia, Porto Alegre, v.58, n.1, p.61-80, 2003. (Série Botânica).

MORAES, C.O.C.; OLIVEIRA, J.C.P. Avaliação agronômica preliminar de genótipos de Bromus auleticus Trinius. Bagé: EMBRAPA / CNPO, 1990. (Circular Técnica, 05).

MURDOCH, A.J.; ELLIS, R.H. Dormancy, viability and longevity. In: FENNER, M. (Ed.). Seeds: the ecology of regeneration in plant communities. 2 ed.Wallingford: CABI, 2000. p.183-214.

NEDEL, J.N. Fundamentos da qualidade de sementes. In: PESKE, S.T.; ROSEnTHAL, M.D.; ROTA, G.R. (Ed.). Sementes: fundamentos científicos e tecnológicos. Pelotas: UFPel, 2003. p.95138.

OLIVEIRA, J.C.P.; MORAES, C.O.C. Distribuição da produção e qualidade de forragem de Bromus auleticus Trinius. Pesquisa Agropecuária Brasileira, Brasília, v.28, n.3, p.391-398, 1993.

OLMOS, F. Bromus auleticus. Tacuarembo: INIA, 1993. 31p. (Série Técnica, 35).

PILLAR, V.D. MULTIV: multivariate exploratory analysis, randomization testing and bootstrap resampling - User's Guide version 2.1. Porto Alegre: UFRGS, 2001. 42p.

RIVEIRO, A.F.; PETIT, M.M. Evaluación primaria de Bromus auleticus. 1982. 124f. Tese (Graduação em Agronomia) Faculdade de Agronomia, Montevideo, Uruguai, 1982.

SILVA, G.M. Efeito de densidade de semeadura e época de colheita sobre o rendimento e a qualidade de sementes de cevadilha vacariana (Bromus auleticus Trinius). 2001. 36f. Dissertação (Mestrado em Ciência e Tecnologia de Sementes) - Faculdade de Agronomia Eliseu Maciel, Universidade Federal de Pelotas, Pelotas, 2001.

SILVA, G.M.; MAIA, M.S.; MORAES, C.O.C. Influência do peso sobre a germinação e o vigor de sementes de cevadilha vacariana (Bromus auleticus Trinius). Informativo ABRATES, Pelotas, v.13, n.3, p.463, 2003.

SILVEIRA, A.L.A.; GOMES, K.E.; OLIVEIRA, J.C.P. Produção e qualidade de cevadilha vacariana (Bromus auleticus Trinius). In: REUNIÓN DE GRUPO TÉCNICO EN FORRAJERAS DEL CONO SUR - ZONA CAMPOS: SISTEMAS DE PRODUCCIÓN: CAMINOS PARA UNA INTEGRACIÓN SUSTENTABLE, 19. 2002, Mercedes. Memorias... Mercedes, Argentina: FAO, 2002. p.235. 
TAMANINI, R.H.V.S. Pastejo e época de colheita na qualidade fisiológica de sementes de cevadilha vacariana (Bromus auleticus Trinius). 2002. 44f. Dissertação (Mestrado em Ciência e Tecnologia de Sementes) - Faculdade de Agronomia Eliseu Maciel, Universidade Federal de Pelotas, Pelotas, 2002.

THEISEN, G. Influência de palha de aveia preta em papuã (Brachiaria plantaginea (Link) Hitchc.) e seu impacto em soja.
1998. 88f. Dissertação (Mestrado em Agronomia) - Faculdade de Agronomia, Universidade Federal do Rio Grande do Sul, Porto Alegre, 1998.

WEINER, J. The influence of competition on plant reproduction. In: LOVETT-DOUST, J.; LOVETT-DOUST, L. (Ed.). Plant Reproductive Ecology. Oxford: Oxford University Press, 1988. p.228-245. 